\title{
Lumbar Canal Diameter Evaluation by CT Morphometry- Study of Indian Population
}

\author{
UTTAM YADAV, MD, ${ }^{1}$ VIVEK SINGH, DNB,${ }^{1}$ NISHANT BHARGAVA, MD,${ }^{1}$ ARUN KUMAR SRIVASTAV, \\ $\mathrm{MCH},{ }^{2}$ ZAFAR NEYAZ, MD, ${ }^{1}$ R.V. PHADKE, MD,${ }^{1}$ PRABHAKAR MISHRA, PHD ${ }^{3}$ \\ ${ }^{I}$ Department of Radiodiagnosis, Sanjay Gandhi Post Graduate Institute Of Medical Sciences (SGPGIMS), Lucknow, India, ${ }^{2}$ Department of Neurosurgery, \\ SGPGIMS, Lucknow, India, ${ }^{3}$ Department of Biostatistics, SGPGIMS, Lucknow, India
}

\begin{abstract}
Study Design: A cross-sectional study.

Background: To document dimensions of the lumbar vertebrae and bony canal in an Indian population and to compare with other studies from the subcontinent as well as from other parts of world.

Methods: An observational study was conducted on the basis of a review of thin-cut ( $3 \mathrm{~mm})$ computed tomographic images of lumbar vertebrae. A total of 302 patients were studied, and various dimensions were analyzed.

Results: In general, the vertebral and bony spinal canal dimensions were found to be greater in male patients. Comparison of populations revealed statistically significant differences in the spinal canal between an Indian population and others.

Overview of Literature: Lumbar canal stenosis is a condition in which the anteroposterior and lateral dimensions of the bony spinal canal are less than normal for corresponding age and sex. Numerous studies have been conducted to determine morphometry of the lumbar vertebrae and spinal canal, mostly in western populations, using fresh cadaver or osteologic specimens. These studies did not mention the difference between the vertebral parameters in men and women. Moreover, many of these studies have limitations such as a small sample size and lack of demographic data including race, age, and sex. In this study, we have conducted morphometric analysis of the lumbar vertebrae in a relatively large number of Indian patients by using computed tomography scan. The morphometric data thus compiled may provide a baseline of body and canal dimensions that could guide clinical experts in their practice.

Conclusions: The dimensions of the lumbar vertebrae and bony canal thus obtained shall provide a baseline normative data for evaluation of patients presenting with low backache and lumbar canal stenosis in an Indian population.
\end{abstract}

Lumbar Spine

Keywords: lumbar canal stenosis, lumbar morphometry, lumbar vertebrae, spinal canal, bony canal, Indian population

\section{INTRODUCTION}

The vertebral column has a complex anatomy and has long been an area of research. Lumbar spondylosis is a problem of adults but is now being increasingly seen in youth, probably due to lifestyle changes. Radiological evaluation forms an important part in evaluation and management of lumbar spondylosis. Multiple factors play a role in spondylosis, but if it is associated with spinal canal stenosis, its management differs. Lumbar canal stenosis is a condition in which the anteroposterior (AP) and lateral dimensions of the bony spinal canal are less than normal for corresponding age and sex. The most common manifestation of lumbar canal stenosis is low backache. Therefore, the dimensions of lumbar vertebrae are very important in clinical diagnosis of lumbar spinal stenosis and lower backache (LBA).

Kirkaldy-Willis et $\mathrm{al}^{1}$ classified lumbar spinal canal stenosis into developmental, degenerative, and other types. Verbiest ${ }^{2}$ showed that the developmental stenosis is due to the properties of the neural arch, pedicles, laminae, and articular processes in which the interpedicular distances are normal, whereas lateral sagittal diameters are shortened due to thickened laminae and articular processes. The degenerative stenosis with secondary osteoarthritis of the segmental spine is more marked opposite the intervertebral disc and posterior articular processes, whereas AP and lateral diameters may be normal.

The combined stenosis shows overall narrowing of the spinal canal or segmental narrowing, protru- 
Table 1. Age distribution.

\begin{tabular}{lccc}
\hline Age, $\mathbf{y}$ & Men & Women & n (\%) \\
\hline $20-25$ & 50 & 44 & $94(31.1)$ \\
$25-30$ & 47 & 35 & $82(27.2)$ \\
$30-35$ & 50 & 36 & $86(28.5)$ \\
$35-40$ & 27 & 13 & $40(13.2)$ \\
\hline
\end{tabular}

sion of a disc, or any combination of these, associated with more neurological symptoms than developmental and degenerative types are.

Numerous studies have been conducted to determine morphometry of lumbar vertebrae in a western population using fresh cadaver or osteologic collections. ${ }^{3-5}$ They had adequate sample sizes but lacked demographic data including race, age and sex. ${ }^{6}$ Computed tomographic (CT) images have been used more recently to study lumbar vertebrae. ${ }^{7,8}$ The recent use of CT for the measurements of the different vertebral dimensions such as canal diameter and vertebral dimension has led to better evaluation of vertebral morphometry as compared with $\mathrm{x}$-ray and cadaveric studies. ${ }^{9}$

In this study, we conducted morphometric analysis of the lumbar vertebrae in a relatively large number of patients by using CT scans. The morphometric data thus compiled may provide a baseline of body and canal dimensions that could guide clinical experts in their practice.

\section{MATERIALS AND METHODS}

This observational study was conducted in one of North India's premier tertiary care institutes. A total of 302 patients over a period of 1 year undergoing diagnostic CT scans for abdominal or genitourinary complaints or patients attending the radiology department for a radiological investigation of regions other than the vertebral column pathology or gross spinal pathology during the study period were included in the study. Of 302 patients studied, $174(57.6 \%)$ were men and 128 (42.4\%) were women (Table 1).

Exclusion criteria included all individuals with age $<20$ years or age $>40$ years, with gross spinal pathology and neurological deficit due to spinal condition, major chronic systemic disease such as chronic liver diseases and chronic kidney diseases, clinically labeled as dwarfism, movement artifact, or metallic artifact.

A CT scan was performed using 64-slice and 128slice multi-detector CT. Unenhanced CT was performed from the level of diaphragm to pubic

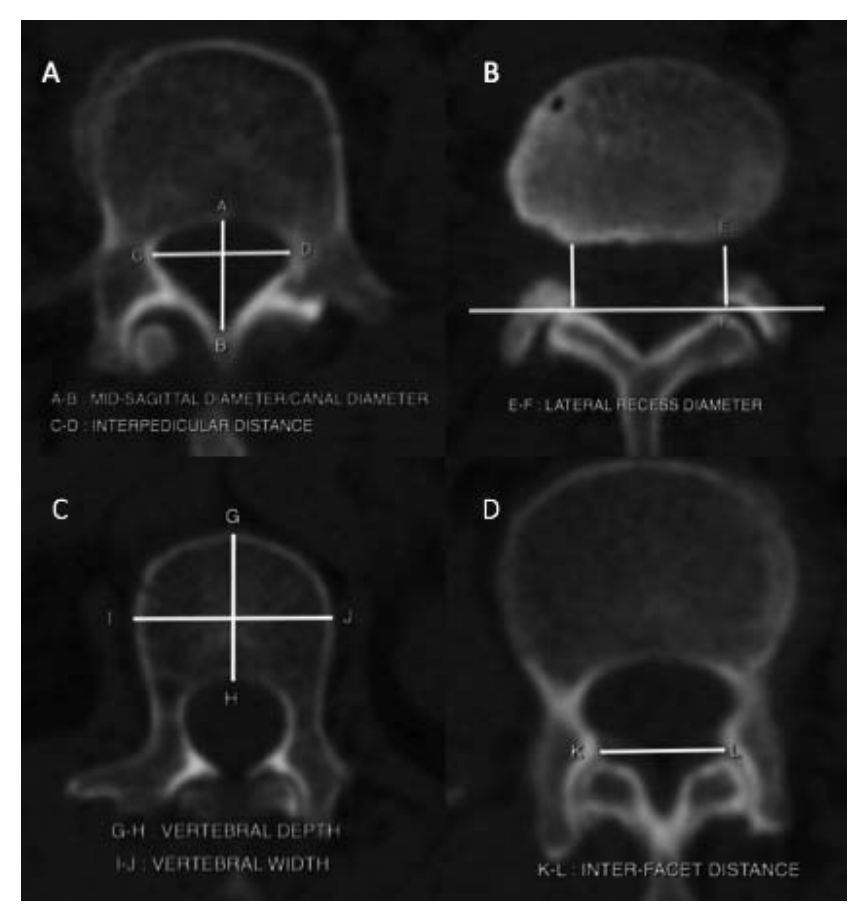

Figure 1. A: Spinal canal diameter/midsagittal diameter-(A-B) Distance between posterior border of the vertebrae to the lamina at the midline. Spinal canal width (interpedicular distance) (C-D) Maximum distance between pedicle. $\mathrm{B}$ : Lateral recess diameter- $(\mathrm{E}-\mathrm{F})$ The distance between the posterior aspect of the vertebral body and anteromedial point of facet joints. C: Vertebral depth$(\mathrm{G}-\mathrm{H})$ Distance between anterior and posterior end of vertebral body in the plane of the upper and lower end plate respectively. Vertebral width-(I-J) Distance between the lateral border of the vertebral body in the plane of the upper and lower end plate respectively. D: Interfacet distance-(K-L) Distance between the anteromedial points of the facet joint.

symphysis with the area to be covered (field of view) from D12 vertebra to S1 vertebra. Sections 3-mm thick with reconstruction up to $1 \mathrm{~mm}$ were analyzed. The images were reconstructed in true axial, coronal, and sagittal planes. The scans were reformatted with bone windows in axial, sagittal, and coronal planes. Measurement was done as shown in Figure 1.

Data were processed and analyzed with SPSS, version 17 (SPSS Inc, Chicago, IL), with $P$ value of .05 set to be significant.

An unpaired $t$ test was used to compare the different dimensions of the lumbar spine of Indian patients with those of other populations, and an independent $t$ test was used to compare male and female populations.

\section{RESULTS}

In our study, we measured different parameters of each vertebra from D12 to S1. For simplicity, we divided these parameters broadly into 2 groups:

1. Vertebral dimensions include upper and 
Table 2. Canal dimensions (mean $\pm \mathrm{SD}$ ).

\begin{tabular}{|c|c|c|c|c|c|c|c|}
\hline \multirow[b]{2}{*}{ Level } & \multirow[b]{2}{*}{$\mathbf{n}$} & \multirow{2}{*}{$\begin{array}{c}\text { Spinal Canal } \\
\text { Depth, mm }\end{array}$} & \multicolumn{2}{|c|}{ Lateral Recess Diameter, mm } & \multicolumn{2}{|c|}{ Intervertebral Foramen Diameter, mm } & \multirow{2}{*}{$\begin{array}{c}\text { Interfacet } \\
\text { Distance, } \mathrm{mm} \\
\end{array}$} \\
\hline & & & Right & Left & Right & Left & \\
\hline \multicolumn{8}{|l|}{ D12 } \\
\hline M & 174 & $16.19 \pm 1.26$ & $11.451 \pm 1.61$ & $11.609 \pm 1.64$ & $10.62 \pm 1.17$ & $10.50 \pm 1.24$ & $15.12 \pm 2.46$ \\
\hline $\mathrm{F}$ & 128 & $16.33 \pm 1.52$ & $9.469 \pm 1.24$ & $9.67 \pm 1.35$ & $10.43 \pm 1.37$ & $10.46 \pm 1.44$ & $14.33 \pm 2.02$ \\
\hline \multicolumn{8}{|c|}{$2000-10$} \\
\hline M & 174 & $15.68 \pm 1.51$ & $11.36 \pm 0.68$ & $11.52 \pm 1.70$ & $10.54 \pm 1.32$ & $10.44 \pm 1.29$ & $17.27 \pm 2.02$ \\
\hline F & 128 & $15.85 \pm 1.43$ & $9.4 \pm 1.29$ & $9.6 \pm 1.38$ & $10.40 \pm 1.37$ & $10.41 \pm 1.31$ & $16.21 \pm 2.06$ \\
\hline \multicolumn{8}{|c|}{$10.00-1.70$} \\
\hline M & 174 & $14.57 \pm 1.59$ & $10.52 \pm 1.39$ & $10.55 \pm 1.41$ & $10.50 \pm 1.69$ & $10.42 \pm 1.80$ & $17.53 \pm 2.15$ \\
\hline $\mathrm{F}$ & 128 & $14.74 \pm 1.38$ & $9.22 \pm 0.91$ & $9.28 \pm 0.92$ & $10.21 \pm 1.49$ & $10.22 \pm 1.50$ & $16.79 \pm 2.14$ \\
\hline \multicolumn{8}{|c|}{ (n) } \\
\hline M & 174 & $13.45 \pm 1.75$ & $9.24 \pm 0.91$ & $9.3 \pm 0.92$ & $9.72 \pm 1.29$ & $9.64 \pm 1.44$ & $17.67 \pm 2.42$ \\
\hline $\mathrm{F}$ & 128 & $13.66 \pm 1.42$ & $8.58 \pm 0.98$ & $8.69 \pm 0.99$ & $9.90 \pm 1.57$ & $10.30 \pm 3.43$ & $16.95 \pm 2.22$ \\
\hline \multicolumn{8}{|c|}{$10.00-1.12$} \\
\hline M & 174 & $13.29 \pm 1.83$ & $8.6 \pm 0.99$ & $8.71 \pm 1.01$ & $8.68 \pm 1.38$ & $8.68 \pm 1.43$ & $19.08 \pm 3.21$ \\
\hline $\mathrm{F}$ & 128 & $13.40 \pm 1.68$ & $8.69 \pm 0.67$ & $7.77 \pm 0.63$ & $8.88 \pm 1.24$ & $8.95 \pm 1.35$ & $18.37 \pm 3.12$ \\
\hline \multicolumn{8}{|c|}{$10.70-1.00$} \\
\hline M & 174 & $14.73 \pm 3.09$ & $7.71 \pm 0.66$ & $7.80 \pm 0.62$ & $8.32 \pm 1.48$ & $8.07 \pm 1.54$ & $22.69 \pm 3.91$ \\
\hline $\mathrm{F}$ & 128 & $14.67 \pm 2.72$ & $7.53 \pm 0.66$ & $7.62 \pm 0.62$ & $8.14 \pm 1.47$ & $8.02 \pm 1.56$ & $21.70 \pm 3.80$ \\
\hline \multicolumn{8}{|c|}{ 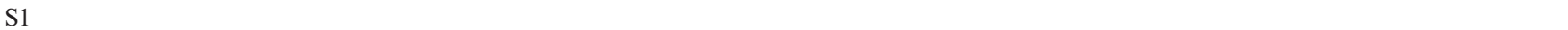 } \\
\hline M & 174 & $11.00 \pm 3.29$ & $7.50 \pm 0.62$ & $7.61 \pm 0.61$ & $5.77 \pm 1.34$ & $5.57 \pm 1.31$ & $27.91 \pm 4.65$ \\
\hline $\mathrm{F}$ & 128 & $11.19 \pm 4.73$ & $7.45 \pm 0.61$ & $7.56 \pm 0.60$ & $5.80 \pm 1.43$ & $5.75 \pm 1.38$ & $26.89 \pm 4.68$ \\
\hline
\end{tabular}

lower vertebral width, upper and lower vertebral depth, and intervertebral disc height.

2. Canal dimensions includes spinal canal AP diameter, lateral recess diameter, intervertebral foramen diameter, and interfacet distance.

We measured the different dimensions of vertebrae and compared between men and women by applying an independent $t$ test. We also compared our study with other studies.

\section{Canal Diameters}

The diameters of the spinal canal were found to change both transversely and anteroposteriorly from D12 to S1. The AP diameters of the spinal canal gradually decreased from D12 to L4, followed by an increase at L5 and then a decrease from L5 to $\mathrm{S} 1$ both in men and women; thus, it was observed that the shape of the spinal canal was changing cranio-caudally from circular to oval. The maximum spinal canal depth (SCD) was noted at the D12 level (in men, $\mathrm{SCD}=16.19 \mathrm{~mm}$; in women, $\mathrm{SCD}=16.33 \mathrm{~mm}$ ) and minimum spinal canal depth was noted at the $\mathrm{S} 1$ level (in men, $\mathrm{SCD}=11.00 \mathrm{~mm}$; in women, $\mathrm{SCD}=11.19 \mathrm{~mm}$ ). There was not much difference in SCDs between the vertebrae of men and women $(P>.05)$, but values of the AP diameter of the spinal cord were greater in women than in men (Table 2).
The right and left lateral recess diameter (LRD) gradually decreased from D12 to S1 in both men and women, as depicted in Table 2. The maximum LRD was noted at D12 (in men, right $\mathrm{LRD}=11.45$ $\mathrm{mm}$, left $\mathrm{LRD}=11.60 \mathrm{~mm}$; in women, right LRD = $9.46 \mathrm{~mm}$, left $\mathrm{LRD}=9.67 \mathrm{~mm}$ ). The minimum LRD was noted at $\mathrm{S} 1$ (in men, right $\mathrm{LRD}=7.50 \mathrm{~mm}$, left $\mathrm{LRD}=7.61 \mathrm{~mm}$; in women, right $\mathrm{LRD}=7.45 \mathrm{~mm}$, left $\mathrm{LRD}=5.80 \mathrm{~mm})$. The LRD was significantly more in men from the D12 to L5 vertebrae $(P<$ $.05)$. There was a significant difference between right and left diameters at all levels $(P<.05)$.

The right and left intervertebral foramen diameter (IVFD) constantly decreased from D12 to S1 in both men and women, as depicted in Table 2. The maximum IVFD was noted at D12 (in men, right IVFD $=10.62 \mathrm{~mm}$, left IVFD $=10.50 \mathrm{~mm}$; in women, right IVFD $=10.43 \mathrm{~mm}$, left IVFD $=10.46$ $\mathrm{mm}$ ). The minimum IVFD was noted at S1 (in men, right $\mathrm{IVFD}=5.77 \mathrm{~mm}$, left $\mathrm{IVFD}=5.57 \mathrm{~mm}$; in women, right $\mathrm{IVFD}=5.80 \mathrm{~mm}$, left IVFD $=5.75$ $\mathrm{mm})$. There was no significant difference between men and women at all levels. A significant difference between right and left was seen only at the S1 level $(P<.05)$.

Interfacet distance (IFD) increased gradually from D12 to $\mathrm{S} 1$ in both men and women. The minimum IFD was noted at D12 (in men, IFD = $15.12 \mathrm{~mm}$; in women, IFD $=14.33 \mathrm{~mm}$ ). The maximum IFD was noted at $\mathrm{S} 1$ (in men, IFD = $27.91 \mathrm{~mm}$; in women, IFD = $26.89 \mathrm{~mm}$ ). The IFD 
Table 3. Vertebral dimensions (Mean $\pm S D$ ).

\begin{tabular}{lcccccc}
\hline Level & $\mathbf{n}$ & UV Width $(\mathbf{m m})$ & UV Depth $(\mathbf{m m})$ & LV Width $(\mathbf{m m})$ & LV Depth $(\mathbf{m m})$ & IVD Height $(\mathbf{m m})$ \\
\hline D12 & & & & & & \\
M & 174 & $36.99 \pm 2.89$ & $27.09 \pm 2.59$ & $39.30 \pm 3.16$ & $27.88 \pm 2.53$ & $6.45 \pm 1.27$ \\
F & 128 & $34.62 \pm 2.82$ & $25.10 \pm 2.46$ & $36.73 \pm 2.99$ & $25.82 \pm 2.73$ & $6.35 \pm 1.27$ \\
L1 & & & & & \\
M & 174 & $40.15 \pm 3.09$ & $28.61 \pm 2.61$ & $42.26 \pm 4.50$ & $29.49 \pm 2.90$ & $7.33 \pm 1.48$ \\
F & 128 & $36.95 \pm 3.14$ & $26.53 \pm 2.22$ & $39.85 \pm 3.13$ & $27.31 \pm 3.24$ & \\
L2 & 174 & $42.55 \pm 4.08$ & $30.37 \pm 3.26$ & $44.35 \pm 3.27$ & $30.60 \pm 2.60$ & $8.66 \pm 1.68$ \\
M & 128 & $39.49 \pm 2.97$ & $28.30 \pm 2.36$ & $42.07 \pm 5.53$ & $29.00 \pm 2.39$ & $8.45 \pm 1.41$ \\
F & 174 & $44.34 \pm 3.17$ & $31.37 \pm 2.78$ & $46.66 \pm 3.38$ & $31.25 \pm 2.39$ & $9.76 \pm 1.80$ \\
L3 & 128 & $41.54 \pm 3.47$ & $29.77 \pm 2.87$ & $43.98 \pm 3.44$ & $29.58 \pm 2.28$ & $10.17 \pm 6.87$ \\
M & 174 & $46.42 \pm 3.98$ & $31.56 \pm 2.27$ & $46.86 \pm 3.85$ & $32.15 \pm 3.04$ & $10.60 \pm 1.76$ \\
F (n=128) & 128 & $43.59 \pm 3.58$ & $30.12 \pm 2.22$ & $44.92 \pm 3.32$ & $30.00 \pm 3.29$ & $10.23 \pm 1.65$ \\
L4 & 174 & $48.79 \pm 5.54$ & $32.41 \pm 2.35$ & $46.93 \pm 3.36$ & $31.66 \pm 2.89$ & $9.82 \pm 1.99$ \\
M & 128 & $46.00 \pm 3.66$ & $30.94 \pm 2.41$ & $45.91 \pm 3.39$ & $30.30 \pm 2.52$ & $9.37 \pm 2.25$ \\
F & & & & & \\
L5 & 174 & $49.08 \pm 4.40$ & $31.16 \pm 3.19$ & $30.78 \pm 3.45$ & $22.78 \pm 2.66$ & $3.55 \pm 0.87$ \\
M & 128 & $46.17 \pm 4.74$ & $29.47 \pm 3.09$ & $29.67 \pm 4.46$ & $22.03 \pm 2.98$ & $3.35 \pm 0.87$ \\
F & & & & &
\end{tabular}

Abbreviations: LV, lower vertebral; UV, upper vertebral.

was significantly $(P<.05)$ larger in men from the D12 to L5 vertebrae (Table 2).

\section{Dimensions of Vertebral Body}

Significant differences were noted between men and women in most of the dimensions of lumbar vertebral bodies.

Upper vertebral width (UVW) progressively increased from D12 to S1 in both men and women, as depicted in Table 3. The minimum UVW was noted at D12 (in men, UVW $=36.99 \mathrm{~mm}$; in women, $\mathrm{UVW}=34.62 \mathrm{~mm}$ ). The maximum UVW was noted at S1 (in men, UVW $=49.08 \mathrm{~mm}$; in women, UVW $=46.17 \mathrm{~mm}$ ). The UVW was significantly larger in men at all levels $(P<.05)$.

Lower vertebral width (LVW) gradually increased from D12 to L5, followed by a decrease at the $\mathrm{S} 1$ level in both men and women. The minimum LVW was noted at $\mathrm{S} 1$ (in men, $\mathrm{LVW}=30.78 \mathrm{~mm}$; in women, LVW $=29.67 \mathrm{~mm}$ ). The maximum LVW was noted at L5 (in men, LVW $=46.93 \mathrm{~mm}$; in women, $\mathrm{LVW}=45.91 \mathrm{~mm}$. The $\mathrm{LVW}$ was significantly larger in men at all levels $(P<.05$; Table 3).

Upper vertebral depth (UVD) progressively increased from D12 to L5, then it decreased at S1 in both men and women. The minimum UVD was noted at D12 (in men, UVD $=27.09 \mathrm{~mm}$; in women, $\mathrm{UVD}=25.10 \mathrm{~mm}$ ). The maximum UVD was noted at L5 (in men, UVD $=32.41 \mathrm{~mm}$; in women, $\mathrm{UVD}=$ $30.94 \mathrm{~mm})$. The UVD was significantly $(P<.05)$ larger in men at all levels (Table 3 ).
Lower vertebral depth (LVD) increased from D12 to L4, followed by a decrease from L 5 to $\mathrm{S} 1$ in men, but in women it progressively increased from D12 to L5, followed by a decrease at S1. The minimum LVD was noted at $\mathrm{S} 1$ (in men, LVD = $22.78 \mathrm{~mm}$; in women, LVD $=22.03 \mathrm{~mm}$ ). The maximum LVD was noted at L4 in men $(\mathrm{LVD}=$ $32.15 \mathrm{~mm}$ ) and in women at the L5 level (LVD = $30.30 \mathrm{~mm})$. The LVD was significantly $(P<.05)$ more in men at all levels (Table 3 ).

Intervertebral disc height (IVDH) gradually increased from D12 to L4, but decreased progressively from L5 to S1 in both men and women, as depicted in Table 3. The minimum IVDH was noted at $\mathrm{S} 1$ (in men, $\mathrm{IVDH}=3.55 \mathrm{~mm}$; in women, $\mathrm{IVDH}=$ $3.35 \mathrm{~mm}$ ). The maximum IVDH was noted at L4 (in men, IVDH $=10.60 \mathrm{~mm}$; in women, $\mathrm{IVDH}=10.23$ $\mathrm{mm})$. The IVDH was significantly larger in men at all levels $(P<.05)$.

\section{DISCUSSION AND COMPARISON WITH OTHER STUDIES}

Low backache is the most common complaint requiring radiological investigations in current setup. ${ }^{10}$ Assessment of lumbar canal size is one of the most essential steps in diagnosing LBA. ${ }^{11}$ Any pathological changes in the structures that surround the spinal canal and foramina may disturb the alignment of the spinal canal in the lumbar region, resulting in LBA. ${ }^{11}$ Hence, the morphology of the lumbar vertebrae shows regional curvatures on the 
Table 4. Spinal canal anteroposterior diameter comparison with other studies.

\begin{tabular}{lcccc}
\hline & $\begin{array}{c}\text { Our Study } \\
\text { (Men), } \\
\mathbf{n}=\mathbf{1 7 4}\end{array}$ & $\begin{array}{c}\text { Our Study } \\
\text { (Women), } \\
\mathbf{n}=\mathbf{1 2 8}\end{array}$ & $\begin{array}{c}\text { Kumar et al }^{\mathbf{7}} \\
\text { (Men), } \\
\mathbf{n = 6 1}\end{array}$ & $\begin{array}{c}\text { Kumar et a }^{\mathbf{7}} \\
\text { (Women), } \\
\mathbf{n = 6 1}\end{array}$ \\
\hline L1 & $16.19 \pm 1.51$ & $16.33 \pm 1.43$ & 16.35 & 16.7 \\
L2 & $14.57 \pm 1.59$ & $14.74 \pm 1.38$ & 15.2 & 16.6 \\
L3 & $13.45 \pm 1.75$ & $13.60 \pm 1.42$ & 14.8 & 15.9 \\
L4 & $13.29 \pm 1.83$ & $13.40 \pm 1.68$ & 13.8 & 14.5 \\
L5 & $14.73 \pm 3.09$ & $14.67 \pm 2.72$ & 15.4 & 14.25 \\
\hline
\end{tabular}

sagittal plane that are necessary for absorbing impact and reducing stiffness. ${ }^{10}$

Lumbar spinal stenosis is a result of a narrowing of the bony spinal canal or intervertebral foramina, resulting in secondary compression of the spinal cord traversing centrally and spinal nerve roots traversing laterally through the intervertebral foramina. Clinically, lumbar spinal stenosis presents as LBA, paresthesia, and bilateral lower limb pain. $^{12,13}$ The data thus presented in our study provide relevant clinical and anatomical information on lumbar vertebral and canal dimensions in a relatively large sample size.

Population-specific variations in dimensions of body segments exist, thus necessitating continuous data gathering of lumbar dimensions in various population groups. In addition, whereas most studies have been done on a western population using cadaveric samples, no reliable source exists for an Indian population that also uses CT data. Hence, it is necessary to have a large data set to compare with radiographic and osteologic techniques with a view to providing a reference standard for lumbar dimensions within the Indian population group.

\section{Canal Diameters}

The AP diameters of the spinal canal gradually decreased from D12 to L4 but marginally increased at L5 and then decreased from L5 to S1 in both men and women; thus, the shape of the spinal canal was changing from circular to oval. The values of the AP diameter of the spinal cord were greater in women than in men. Similar results were observed in the Telangana population by Kumar et $\mathrm{al}^{7}{ }^{7}$ who examined CT-scan-based measurements of the lumbar spine in 61 adult patients (Table 4).

Right and left LRD decreased from D12 to S1 in both men and women. Significant difference was found between men and women in LRD, which was significantly larger in men at the D12 to L5 vertebrae $(P<.05)$. There was significant difference between right and left diameters at all levels $(P<$ $.05)$. A similar pattern was also observed by Alam et $\mathrm{al}^{14}$ in a Pakistani population for both men and women (Table 5).

Right and left IVFD constantly decreased from D12 to S1 in both men and women. The maximum IVFD was noted at D12 and the minimum IVFD was noted at $\mathrm{S} 1$. There was no significant difference $(P>.05)$ between men and women at all levels. Significant difference between right and left was seen only at the $\mathrm{S} 1$ level $(P<.05)$.

Interfacet distance increased gradually from D12 to $\mathrm{S} 1$ in both men and women. The minimum IFD was noted at D12 and the maximum IFD was noted at S1. The IFD was significantly larger in men at all levels $(P<.05)$.

\section{Vertebral Dimensions}

Upper vertebral width increased from D12 to S1 in both men and women. Similar results were found by Singh et $\mathrm{al}^{15}$ on a study of 20 cadavers. Alam et $\mathrm{al}^{14}$ studied a Pakistani population and Kang et $\mathrm{al}^{16}$ studied a Korean population using CT morphometry; in both studies, researchers observed similar trends of an increase of UVW cranio-caudally from L1 to L5 (Table 6).

Lower vertebral width increased from D12 to L5 but decreased at the $\mathrm{S} 1$ level in both men and women. Lower vertebral width was significantly

Table 5. Lateral recess diameter comparison with other studies.

\begin{tabular}{|c|c|c|c|c|c|c|c|c|}
\hline & \multicolumn{4}{|c|}{ Present Study $(n=302)$} & \multicolumn{4}{|c|}{ Alam et al $^{14}(n=49)$} \\
\hline & \multicolumn{2}{|c|}{ Male } & \multicolumn{2}{|c|}{ Female } & \multicolumn{2}{|c|}{ Male } & \multicolumn{2}{|c|}{ Female } \\
\hline & Right & Left & Right & Left & Right & Left & Right & Left \\
\hline L1 & $11.36 \pm 0.68$ & $11.52 \pm 1.70$ & $9.4 \pm 1.29$ & $9.6 \pm 1.38$ & 9.7 & 10.1 & 9.5 & 9.5 \\
\hline $\mathrm{L} 2$ & $10.52 \pm 1.39$ & $10.55 \pm 1.41$ & $9.22 \pm 0.91$ & $9.28 \pm 0.92$ & 9.3 & 9.65 & 8.83 & 9.067 \\
\hline L3 & $9.24 \pm 0.91$ & $9.3 \pm 0.92$ & $8.58 \pm 0.98$ & $8.69 \pm 0.99$ & 8.56 & 8.562 & 8.17 & 8.1 \\
\hline L4 & $8.6 \pm 0.99$ & $8.71 \pm 1.01$ & $8.69 \pm 0.67$ & $7.77 \pm 0.63$ & 7.82 & 7.77 & 6.74 & 6.85 \\
\hline L5 & $7.71 \pm 0.66$ & $7.80 \pm 0.62$ & $7.53 \pm 0.66$ & $7.62 \pm 0.62$ & 7.05 & 6.64 & 6.66 & 6.64 \\
\hline
\end{tabular}


Table 6. Upper vertebral width comparison with other studies.

\begin{tabular}{|c|c|c|c|c|c|c|c|}
\hline & \multicolumn{2}{|c|}{ Our Study $(N=302)$} & \multicolumn{2}{|c|}{ Alam et al $^{14}(\mathrm{~N}=49)$} & \multicolumn{2}{|c|}{ Kang et al $^{16}(N=60)$} & \multirow[b]{2}{*}{ Jaskaran et al $^{15}(\mathrm{~N}=20)$} \\
\hline & Male & Female & Male & Female & Male & Female & \\
\hline L1 & $40.15 \pm 3.09$ & $36.95 \pm 3.14$ & 41.7 & 38.4 & $41.98 \pm 2.8$ & $35.55 \pm 2.19$ & $41.4 \pm 2.83$ \\
\hline L2 & $42.55 \pm 4.08$ & $39.49 \pm 2.97$ & 43.44 & 39.5 & $43.8 \pm 2.96$ & $37.3 \pm 2.58$ & $44 \pm 3.23$ \\
\hline L3 & $44.34 \pm 3.17$ & $41.54 \pm 3.47$ & 45.45 & 40.88 & $46.31 \pm 3.44$ & $40.71 \pm 2.70$ & $46.2 \pm 3.95$ \\
\hline L4 & $46.42 \pm 3.98$ & $43.59 \pm 3.58$ & 47.08 & 43.43 & $48.06 \pm 3.37$ & $43.77 \pm 3.30$ & $48.3 \pm 3.17$ \\
\hline L5 & $48.79 \pm 5.54$ & $46 \pm 3.66$ & 48.95 & 46.24 & $54.83 \pm 4.31$ & $49.72 \pm 4.59$ & $50.3 \pm 4.64$ \\
\hline
\end{tabular}

larger in men at all levels $(P<.05)$. A similar study by Singh et $\mathrm{al}^{15}$ on 20 cadavers from a north Indian population noted that LVW increased from L1 to L2 then decreased at L3, followed by an increase from L3 to L5. This pattern was not seen in our study. Alam et $\mathrm{al}^{14}$ conducted a study of measurement of lumbar vertebrae by CT scan on 49 patients from a Pakistani population and noted similar patterns in both men and women, as seen in our study. The values of LVW was greater in men than in women, similar to our study (Table 7).

Upper vertebral depth increased from D12 to L5, then it decreased at S1 in both men and women. Upper vertebral depth was significantly larger in men at all levels $(P<.05)$. A similar pattern also was observed by Alam et $\mathrm{al}^{14}$ in a Pakistani population in both men and women. The values of UVD were greater in men than in women at all levels, similar to our study (Table 8).

Lower vertebral depth increased from D12 to L4, followed by a decrease from L5 to S1 in men, but in women it progressively increased from D12 to L5, followed by decrease at $\mathrm{S} 1$. The minimum LVD was noted at S1 in both men and women, and the maximum LVD was noted in men and in women at L4 and L5, respectively. Lower vertebral depth was significantly larger in men than in women at all levels $(P<.05)$. Similar patterns were observed in a study on a Pakistani population by Alam et al. ${ }^{14}$

Intervertebral disc height gradually increased from D12 to L4, followed by a progressive decrease from L 5 to $\mathrm{S} 1$ in both men and women. In both men and women, minimum and maximum IVDH were noted at the S1 and L4 levels, respectively. Intervertebral disc height was significantly larger in men at all levels $(P<.05)$.

\section{CONCLUSIONS}

In our study, we measured different parameters (vertebral and canal diameters) of vertebrae from D12 to S1 in an Indian population with the help of $\mathrm{CT}$ scans in a relatively large number of patients $(\mathrm{N}$ $=302$ ), which was more clinically relevant and accurate in contrast to cadaveric or manually measured data. We compared our study with other studies from the same subcontinent as well as from other parts of world. The present study also provided a comparison between men and women, and we found significant differences in various dimensions of lumbar vertebrae.

The AP diameters of the spinal canal gradually decreased from D12 to L4, followed by an increase at L5, and then decreased from L5 to S1 both in men and women. On comparison, similar trends were noted with other studies, but the values were lower in our research. Vertebral dimensions (vertebral width, vertebral depth) progressively increased from D12 to S1. On comparison, similar trends were observed in other studies.

The dimensions of the lumbar vertebrae and bony canal thus obtained will provide a baseline normative data for evaluation of patients presenting with LBA and lumbar canal stenosis in an Indian population.

Table 7. Lower vertebral width comparison with other studies.

\begin{tabular}{|c|c|c|c|c|c|}
\hline & $\begin{array}{c}\text { Our Study, } \\
\text { Male }(\mathrm{n}=174)\end{array}$ & $\begin{array}{c}\text { Our Study, } \\
\text { Female }(\mathrm{n}=128)\end{array}$ & $\begin{array}{c}\text { Jaskaran et al }^{15} \\
(n=20)\end{array}$ & $\begin{array}{c}\text { Alam et al, }{ }^{14} \\
\text { Male }(\mathrm{n}=33)\end{array}$ & $\begin{array}{c}\text { Alam et al, }{ }^{14} \\
\text { Female }(\mathrm{n}=16)\end{array}$ \\
\hline L1 & $42.26 \pm 4.50$ & $39.85 \pm 3.13$ & $44.6 \pm 3.35$ & 42.5 & 38.9 \\
\hline $\mathrm{L} 2$ & $44.35 \pm 3.27$ & $42.07 \pm 5.53$ & $46.8 \pm 3.41$ & 44.69 & 40.7 \\
\hline L3 & $46.66 \pm 3.38$ & $43.98 \pm 3.44$ & $41.3 \pm 3.34$ & 45.39 & 42.35 \\
\hline L4 & $46.86 \pm 3.85$ & $44.92 \pm 3.32$ & $50.9 \pm 3.06$ & 46.91 & 43.51 \\
\hline L5 & $46.93 \pm 3.36$ & $45.91 \pm 3.39$ & $50.6 \pm 4.62$ & 47.04 & 44.9 \\
\hline
\end{tabular}


Table 8-. Upper vertebral depth (anteroposterior diameter) comparison with other studies.

\begin{tabular}{lcrllc}
\hline & \multicolumn{2}{c}{ Our Study $(\mathbf{n}=\mathbf{3 0 2})$} & & \multicolumn{2}{c}{ Alam et $\mathbf{~ a l}^{\mathbf{1 4}}(\mathbf{n}=\mathbf{4 9})$} \\
\cline { 2 - 3 } \cline { 5 - 6 } & \multicolumn{1}{c}{ Male } & \multicolumn{1}{c}{ Female } & & Male & Female \\
\hline L1 & $28.61 \pm 2.61$ & $26.53 \pm 2.22$ & & 30.4 & 27.7 \\
L2 & $30.37 \pm 3.26$ & $28.3 \pm 2.36$ & & 32.47 & 29.6 \\
L3 & $31.37 \pm 2.78$ & $29.77 \pm 2.87$ & & 32.85 & 30 \\
L4 & $31.56 \pm 2.27$ & $30.12 \pm 2.22$ & & 33.85 & 30 \\
L5 & $32.41 \pm 2.35$ & $30.94 \pm 2.41$ & & 33.71 & 31.5 \\
\hline
\end{tabular}

\section{REFERENCES}

1. Kirkaldy-Willis WH, Paine KW, Cauchiox J, McIvor G. Lumbar spinal stenosis. Clin Orthop Relat Res. 1974;(99):30-50.

2. Verbiest H. Results of surgical treatment of idiopathic developmental stenosis of the lumbar vertebral canal. A review of twenty-seven years' experience. J Bone Joint Surg $\mathrm{Br}$. 1977;59(2):181-188.

3. Krag MH, Beynnon MS, Pope MH, et al. An internal fixator for posterior application to short segments of thoracic, lumbar or lumbosacral spine-design and testing. Clin Orthop Rel Res. 1986;203:75-98.

4. Bernhardt M, Swartz DE, Clothiaux PL, Crowell RR, White AA 3rd. Posterolateral lumbar and lumbosacral fusion with and without pedicle screw internal fixation. Clin Orthop Relat Res. 1992;(284):109-115.

5. Misenhimer GR, Peek RD, Wiltse LL, Rothman SL, Widell EH Jr. Anatomic analysis of pedicle cortical and cancellous diameter as related to screw size. Spine (Phila Pa 1976). 1989;14:367-372.

6. Saillant G. Anatomical study of the vertebral pedicles. Surgical application. Rev Chir Orthop Reparatrice Appar Mot. 1976;62:151-160.

7. Kumar AP, Kasturi A, Ramu C, Nadadur S. Morphometric analysis of lumbar vertebrae in tertiary care institutions in Telangana. Ann Int Med Dent Res. 2016;2(1):157-162.

8. Bernard TN Jr, Seibert CE. Pedicle diameter determined by computed tomography. Its relevance to pedicle screw fixation in the lumbar spine. Spine (Phila Pa 1976). 1992;17(suppl 6):S160-S163.

9. Zindrick MR, Wiltse LL, Doornik A, et al. Analysis of the morphometric characteristics of the thoracic and lumbar pedicles. Spine (Phila Pa 1976). 1987;12:160-166.

10. Atta-Alla el SS, Saab IM, El Shishtawy M, Hassan KH.
Morphometric study of the lumbosacral spine and some of its related angles in Lebanese adult females. Ital J Anat Embryol. 2014;119(2):92-105.

11. El-Rakhawy M, El-Rahman El-Shahat A, Labib I, Abdulaziz E. Lumbar vertebral canal stenosis: concept of morphometric and radiometric study of the human lumbar vertebral canal. Anatomy. 2010;4:51-62.

12. Storm PB, Chou D, Tamargo RJ. Lumbar spinal stenosis, cauda equina syndrome, and multiple lumbosacral radiculopathies. Phys Med Rehabil Clin N Am. 2002;13(3):713733.

13. Bajwa NS, Toy JO, Ahn NU. Application of a correlation between the lumbar Torg ratio and the area of the spinal canal to predict lumbar stenosis: a study of 420 postmortem subjects. J Orthop Traumatol. 2013;14(3):207-212.

14. Alam MM, Waqas M, Hussain S, Javed G. Lumbar morphometry: a study of lumbar vertebrae from a Pakistani population using computed tomography scans. Asian Spine J. 2014;8(4):421-426.

15. Singh J, Pahuja K, Khatri JK. Morphometeric analysis of the lumbar vertebrae in north Indian population. Asian $J$ Pharm Health Sci. 2013;3(4):830-834.

16. Kang KS, Song KS, Lee JS, Yang JJ, Song IS. Comparison of radiographic and computed tomographic measurement of pedicle and vertebral body dimensions in Koreans: the ratio of pedicle transverse diameter to vertebral body transverse diameter. Eur Spine J. 2011;20(3):414-421.

Disclosures and COI: The authors received no funding for this study and report no conflicts of interest.

Corresponding Author: Dr Vivek Singh, Associate Professor, Department of Radiodiagnosis, SGPGIMS, Lucknow, India. Phone: 91 8004904503; Email: singhvivek79@rediffmail.com.

Published 30 April 2020

This manuscript is generously published free of charge by ISASS, the International Society for the Advancement of Spine Surgery. Copyright (C) 2020 ISASS. To see more or order reprints or permissions, see http://ijssurgery.com. 